\title{
Caracterização geofísica e estrutural da principal estrutura mineralizada em ouro na região nordeste do Quadrilátero Ferrífero: Um guia para prospecção
}

Madeira T.J.A., Endo I., Barbosa M.S.C. \& Neyer B.O.

Departamento de Geologia - Escola de Minas / UFOP

Copyright 2014, SBGf - Sociedade Brasileira de Geofísica

Este texto foi preparado para a apresentação no VI Simpósio Brasileiro de Geofísica, Porto Alegre, 14 a 16 de outubro de 2014. Seu conteúdo foi revisado pelo Comitê Técnico do VI SimBGf, mas não necessariamente representa a opinião da SBGf ou de seus associados. É proibida a reprodução total ou parcial deste material para propósitos comerciais sem prévia autorização da SBGt.

\section{Resumo}

A interpretação de uma grande quantidade de dados pode ser auxiliada por técnicas de interpretação "automática" como a deconvolução de Euler, Durrheim \& Cooper (1997). Está técnica considera as anomalias produzidas por várias fontes relativamente simples e reproduz as posições e profundidades destas fontes. Estes dados podem, então, serem utilizados como base para uma interpretação mais detalhada. $O$ arcabouço tectônico e as feições geométricas observadas no nordeste do Quadrilátero Ferrífero (QFe) não condizem com a proposta da literatura. Este trabalho, integração da geologia com a geofísica, propõe um modelo tectônico para a área correlacionável aos megadobramentos propostos na literatura para as nappes Curral e Ouro Preto (Almeida 2004, Endo et al. 2005).

\section{Introdução}

A descoberta do Brasil não despertou em Portugal, nas primeiras décadas que a seguiram, qualquer grande interesse exploratório. Durante o século XVII foram encontrados os ricos aluviões auríferos de Minas Gerais, onde o pouco conhecimento da arte da mineração era compensado pela riqueza do jazimento e facilidade de extração do metal, liberado e grosseiro (Silva, 1995). O conhecimento geológico aplicado neste contexto histórico foi amplamente estudados em superfície, culminando em inúmeros trabalhos sobre a mineralização de ouro, sobretudo no domínio da Zona de Cisalhamento São Vicente.

Levantamentos geofísicos aéreos no Brasil eram raros antes da década de 70 . Nesta década e nos primeiros anos da de 80, uma série de levantamentos aerogeofísicos foram realizados pelo DNPM, através da CPRM, cobrindo grandes áreas do País e trazendo enormes contribuições para a compreensão do arcabouço geológico-tectônico das áreas levantadas e de seu potencial mineral. A geofísica vem se mostrando uma ferramenta cada vez mais eficaz no estudo de estruturas e na prospecção mineral, se consolidando como principal ferramenta no estudo de áreas com conhecimento geológico já consolidado em superfície e que necessitam de informações em subsuperfície.

A área de estudo localiza-se na porção norte do Quadrilátero Ferrífero, a sul da Serra da Piedade, na poligonal encerrada pelos municípios de Sabará, Caeté e Raposos. Nessa área, que abrange as quadrículas de Caeté e Belo Horizonte (Baltazar et al. 2005), há o levantamento aerogeofísico do DNPM/CPRM (1996 in Baltazar et al. op cit.) - Projeto Rio das Velhas (Figura 1).

Neste trabalho, a integração da geofísica com a geologia, teve como objetivo precípuo a delineação do arcabouço lito-estrutural do contato entre as Unidades Mestre Caetano e Córrego do Sítio, inseridas no greenstone belt Rio das Velhas. Dentre os objetivos específicos do trabalho, ressalta-se: a proposta do fechamento de um dobramento em padrão de assimetria em "S" ao longo das unidades do greenstone belt, com um anticlinal sinfórmico na região central e um sinclinal antifórmico na região centro-sul. Correlacionáveis aos megadobramentos propostos na literatura para a nappe Curral e a nappe Ouro Preto (i.g. Almeida 2004, Almeida et al. 2005, Endo et al. 2005), com a Zona de Cisalhamento São Vicente marcando o descolamento basal da nappe Ouro Preto, assentando em rochas da Unidade Mestre Caetano

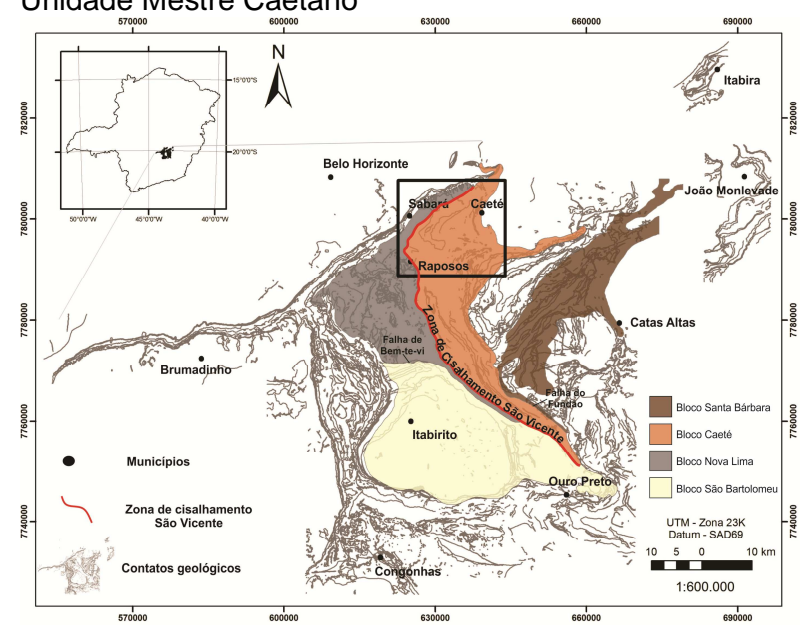

Figura 1 - Mapa de localizaçãao da área no Quadrilátero Ferrífero, bem como da Zona de Cisalhamento São Vicente (modificado de Baltazar et al. 2005).

Estruturalmente o arcabouço proposto na literatura não condiz com as feições geométricas observadas nas rochas. A utilização desta metodologia, ou seja, integração dos dados geológicos aos dados geofísicos, viabiliza a visualização das principais estruturas em profundidade. Contribuindo para 0 conhecimento geológico-tectônico em subsuperfície. 


\section{Metodologia/ Problema Investigado}

Utilizaram-se como base de dados geológicos os mapas do Projeto Geologia do Quadrilátero Ferrífero Integração e Correção Cartográfica em SIG, convênio USGS/DNPM (1952-1969), e a integração ao mapeamento geológico do convênio DNPM/CPRM (19921996). A integração dos projetos supracitados é um SIG do mapa geológico do Quadrilátero Ferrífero, a partir dos mapas 1:25.000 dos projetos USGS/DNPM e DNPM/CPRM (Baltazar et al. 2005).

A base de dados geofísicos sintetiza as informações do Projeto Geologia do Quadrilátero Ferrífero e faz parte do Programa de Distritos Mineiros, DNPM, e de Províncias Minerais, CPRM, denominado Projeto Rio das Velhas (PRV). O PRV, um projeto cooperativo entre governo, indústria e cientistas de universidades, foi realizado entre setembro de 1992 e dezembro de 1995, e representa um dos maiores levantamentos geológicos e geofísicos aéreo de detalhe já realizado no Brasil.

Os dados aerolevantados (arquivo ASCII) foram importados para o Oasis Montaj 7.0.1 e, posteriormente, gerou-se um arquivo ".gdb". Pela rotina WINXY, os dados foram processados possibilitando 0 destaque $e$ identificação das anomalias na área de estudos, pela aplicação de filtros (Carneiro \& Barbosa 2008). Os dados foram interpolados pelo método de mínima curvatura, em malha regular de $300 \mathrm{~m}$ e gerados vários mapas temáticos e uma imagem ternária.

Com o software Euler (versão 1.00) realizou-se a inversão (Deconvolução de Euler) dos dados magnetométricos nos perfis coincidentes com os perfis geológicos levantados em campo, possibilitando a estimativa das estruturas em profundidade.

Os levantamentos de campo possibilitaram uma análise geométrica e cinemática das principais feições estruturais da região, através do detalhamento de 4 seções estruturais e estratigráficas em escala 1:5.000. Amostras orientadas, ao longo dos perfis, contribuíram para os estudos petrográficos e microestruturais nos litotipos característicos e definidores do fluxo tectônico.

A integração e interpretação dos dados estratigráficos, estruturais, petrográficos e geofísicos possibilitaram a confecção de 2 perfis geológico-estrutural e a elaboração de um modelo tectônico.

\section{Resultados}

A história geológica das rochas constituintes dos Supergrupos Rio das Velhas e Minas pertencem a distintos contextos temporais e ambientais, de maneira que o acamamento (Sb) dessas associações de litofácies divergem em posição espacial (Figura 2).

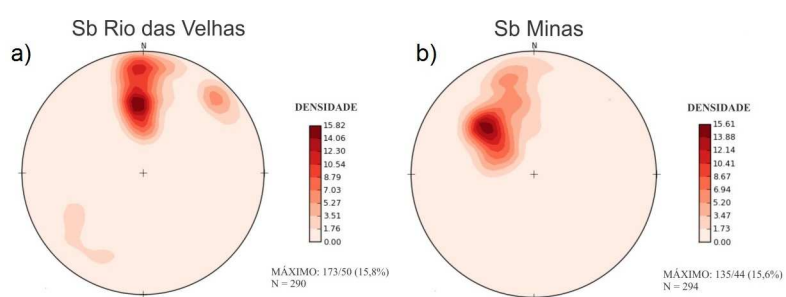

Figura 2: Estereograma do acamamento (Sb) sedimentar observado na área. Em (a) o acamamento das rochas do Supergrupo Rio das Velhas evidenciado pelas variações composicionais de porções micáceas, quartzosas e máficas e, em (b) o acamamento das rochas pertencentes aos Supergrupo Minas manifestado pelas variações composicionais dos itabiritos, mármores e filitos.

Foram reconhecidas três fases deformacionais na evolução tectônica da área.

A primeira fase (Fn-1), de idade arqueana, corresponde ao evento Jequié (Endo 1997) e envolveu as unidades lito-estratigráficas do Complexo Caeté e do greenstone belt Rio das Velhas. Este evento verticalizou 0 acamamento $(\mathrm{Sb})$ e gerou uma foliação penetrativa (Sn1) subparalela que encontra-se, contudo, obliterada em algumas porções do greenstone belt. Quando reconhecida, Sn-1 apresenta-se ora crenulada, de forma discreta pelas fases deformacionais posteriores, e ora plano-paralela. Essa foliação é reconhecida mais facilmente em escala microscópica, sendo melhor preservada nos níveis filíticos apresentando direção NESW com mergulho para NE.

A fase deformacional Fn, de idade Transamazônica, corresponde a orogenia Minas (Endo 1997) e foi responsável por afeiçoar a arquitetura estrutural mais proeminente na região, envolvendo desde o embasamento até as rochas do Supergrupo Minas. Essa deformação é ilustrada por uma foliação penetrativa (Sn), pela lineação de interseção (Li) dos planos SbXSn e, localmente, por uma lineação mineral (Lm) subparalela à Li e que, também, é subparalela aos eixos das dobras mesoscópicas (E-SE) (Figura 3). Estas estruturas caracterizam uma lineação do tipo-b, no sentido de Ramsay (1967), que controla as estruturas correlacionáveis a este evento. Também, ocorrem venulações de quartzo boudinado e escamas de rochas milonitizadas (Figura 3). Ainda, foram registrados dobramentos mesoscópicos e boudins com a mesma cinemática fractal do arcabouço microestrutural. 


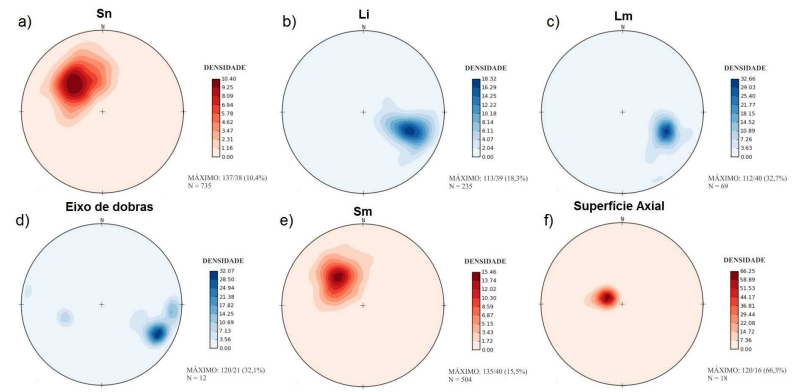

Figura 3: Estereogramas representativos das principais estruturas relacionadas à orogenia Minas de Endo (1997). a) a foliação penetrativa principal - xistosidade $(\mathrm{Sn})$ da região mapeada; b) a lineação de interseção (Li) dos planos de acamamento $(S b)$ e xistosidade $(S n) ; c)$ lineação mineral (sub)paralela à $\mathrm{Li} ; \mathrm{d}$ ) eixo de dobras mesoscópicas; e) foliação milonítica observada em escamas de rochas; $f$ ) superfície axial de dobras mesoscópicas.

A terceira fase deformacional reconhecida $(F n+1)$ relaciona-se ao evento Brasiliano. Apresenta caráter incipiente e pôde ser reconhecida nas Unidades Mindá e Mestre Caetano (Grupo Nova Lima). Essa deformação nucleou clivagens de crenulação (Ccre) disjuntiva a discreta sobre a foliação Sn, apresenta planos de direção $\mathrm{N}$-S com mergulhos variáveis e em alto ângulo para $\mathrm{E}$ e W. As lineações de crenulação (Lcre) associadas a esta deformação exibem trama com sentido do caimento ESE que são distintas nos níveis micáceos (Figura 4).

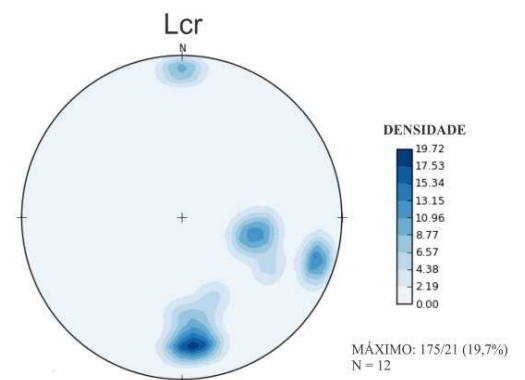

Figura 4: Disposição da lineação de crenulação associada com uma clivagem de crenulação $N-S$ relacionada ao evento Brasiliano.

Foram realizados dois perfis de inversão magnetométrica (Amplitude do Sinal Analítico) nas proximidades das seções geológicas-estruturais levantadas em campo (Figura 5 - Anexo).

Buscando-se maior confiabilidade dos resultados apresentados pelo software Euler, foram testados e avaliados vários parâmetros como tamanho da janela, profundidade e índice estrutural. As janelas fornecem estimativas de localização única da fonte causadora da anomalia magnética e o tamanho utilizado deve ser pequeno, pois quanto menor o tamanho da janela maior será a resolução dos resultados. Para um índice estrutural igual a zero, e.g., são utilizados todos os pontos da janela para resolver a equação de Euler, para a fonte de posição $\mathrm{x}_{0}, \mathrm{y}_{0}, \mathrm{z}_{0}$, e estimar os mínimos quadrados (valores de background da solução) (Madeira
\& Barbosa, 2012). Quando todas as estimativas são inseridas ao longo de um perfil elas tendem a se agrupar em torno do contraste de magnetização. A fim de delimitar os corpos com boas estimativas foram utilizados os seguintes parâmetros: janela com o tamanho 14, índice estrutural igual a 1 e profundidade máxima de estimativa de 7.000m (Figura 5 - Anexo).

$\mathrm{Na}$ Figura 5, os mais altos valores de picos magnetométricos dos perfis de inversão coincidem com o traço da Zona de Cisalhamento São Vicente (Figura 6).

A integração dos dados de campo com os perfis geofísicos possibilitou a confecção de 2 perfis tectonoestruturais. No perfil A-A' (Figura 6) observa-se um mega estrutura anticlinal e o perfil B-B' (Figura 7) apresenta uma mega estrutura sinclinal.

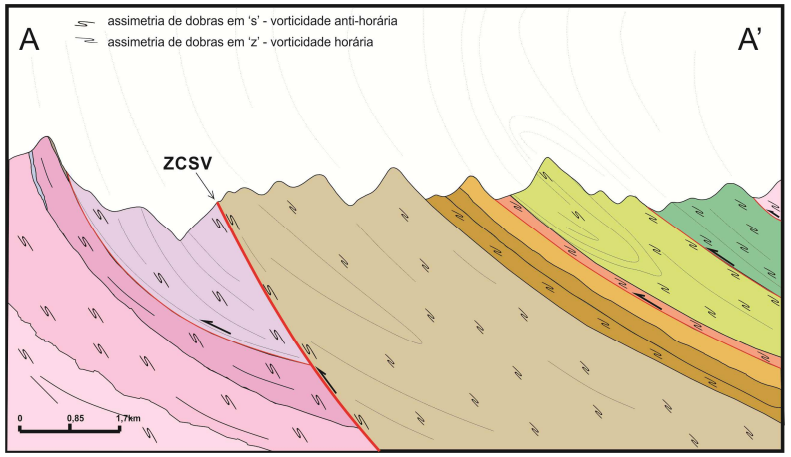

Figura 6: Perfil integrado mostrando a Zona de Cisalhamento São Vicente (ZCSV). A geometria da mega estrutura é uma dobra anticlinal.

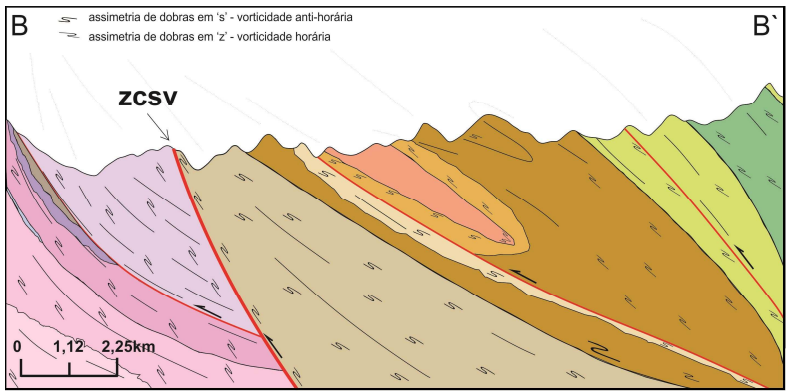

Figura 7: Perfil integrado apresentando a posição da Zona de Cisalhamento São Vicente (ZCSV). A geometria da mega estrutura é uma dobra sinformal.

\section{Discussão e Conclusões}

A discussão dos resultados será abordada de maneira comparativa ao mapa proposto pelo Projeto Rio das Velhas, Baltazar, et al. (2005). A relação geométrica exposta pelo acervo estrutural levantado, aliado a integração de dados geofísicos, mostra que o contato entre as unidades Mestre Caetano e Córrego do Sítio (Figura 8), centro-norte, não condiz com aquele proposto por Baltazar et al. (op cit.). 
No perfil A-A' (Figura 6) as rochas ao norte do contato entre as unidades Mestre Caetano e Córrego do Sítio as estruturas apresentam vorticidade horária, com sigmoide intrafolial em ' $Z$ ', e o pacote de rochas situado a sul do contato registram vorticidade anti-horária. A Unidade Morro Vermelho apresenta, localmente, vorticidade horária registrada pelo mapa Eletromagnético de média frequência (Figura 9). Essas estruturas afeiçoam um anticlinal no domínio nordeste da área.

O perfil B-B` (Figura 7) segue a mesma vorticidade de estruturas que o perfil $\mathrm{A}$, em sua extensão norte. $\mathrm{Na}$ unidade Ribeirão Vermelho ocorrem estruturas mesoscópicas com feições ' $M$ ', correlatas a charneira de dobra. A partir desta unidade a vorticidade cinemática das estruturas é horária e, localmente, ocorrem estruturas do tipo ' $L$ ' tectonito na Unidade Ouro Fino.

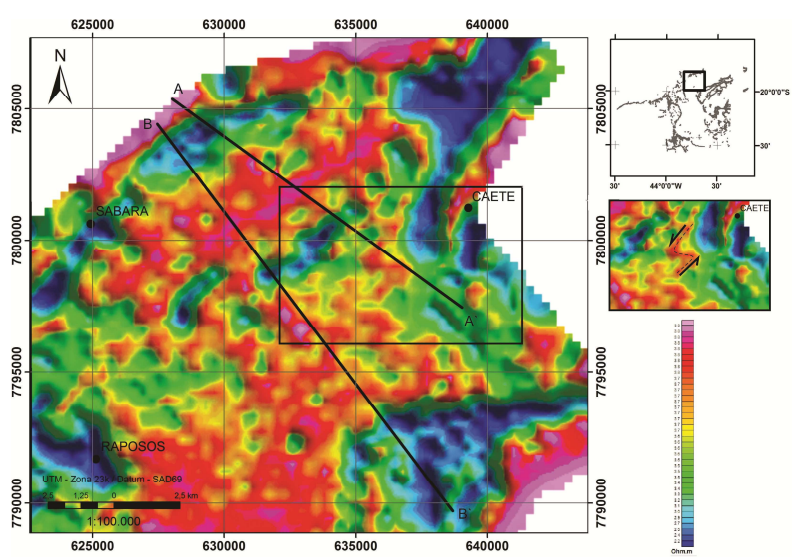

Figura 9: Mapa eletromagnético de média frequência com detalhe sobre a estrutura de vorticidade anti-horária afeiçoada localmente na Unidade Morro Vermelho.

Os registros estruturais do Supergrupo Minas corroboram com a megaestrutura da Nappe Curral, proposta por Endo et al. (2005), de maneira que o descolamento basal da Nappe Ouro Preto situa-se assentado na interface entre as Unidades Mestre Caetano e Córrego do Sítio. Considerando a assembleia litológica e estrutural do greenstone belt, propõem-se o fechamento de uma dobra regional em ' $S$ ', correlacionável ao domínio da Nappe Ouro Preto de Almeida (2004). Nesse contexto, a conexão da Nappe Ouro Preto com a Nappe Curral está materializado na Zona de Cisalhamento São Vicente, que se estende desde as proximidades de Ouro Preto até a porção norte do QFe.

\section{Agradecimentos}

Agradecemos a CPRM Serviço Geológico do Brasil pela permissão de utilizar os dados geológicos e geofísicos para fins acadêmicos.

\section{Referências}

Almeida L.G., Endo, I. \& Fonseca M.A. 2002. Sistema de nappes na porção meridional do Quadrilátero Ferrífero, MG. In: SBG, Congresso Brasileiro de Geologia, 41, João Pessoa, Anais, p. 615.

Almeida L.G. 2004. Estratigrafia e geologia estrutural da porção central do sinclinal Dom Bosco, Quadrilátero Ferrífero - Minas Gerais. MS Dissertation, Dep. De Geologia, Universidade Federal de Ouro Preto, 109 p.

Almeida L.G., Castro P.T.A., Endo I. \& Fonseca M.A., 2005. O Grupo Sabará no Sinclinal Dom Bosco, Quadrilátero Ferrífero: Uma revisão estratigráfica. Ver. Bras. Geociências. 35(2) 177-186.

Baltazar O.F., Baars F.J., Lobato L.M., Reis L.B., Achtschin A.B., Berni G.V. \& Silveira V.D., 2005. Mapa Geológico do Quadrilátero Ferrífero na Escala 1: 50.000 com Nota Explicativa. In: Projeto Geologia do Quadrilátero Ferrífero - Integração e Correção Cartográfica em SIG com Nota Explicativa. Lobato et al. (2005) CODEMIG. Belo Horizonte.

Carneiro M.A. \& Barbosa S.C., 2008. Implicações geológicas e tectônicas da interpretação magnetométrica da região de Oliveira, Minas Gerais. Rev. Bras. Geof., 26(1):87-98.

Durrheim R.J. \& Cooper G.R.J., 1998. EULDEPÇ a program for the Euler deconvolution of magnetic and gravity data. Elsevier - Computer \& Geosciences. 24(6): 545-550.

Endo I. 1997. Regimes tectônicos do arqueano e proterozóico no interior da placa sanfranciscana: Quadrilátero Ferrífero e áreas adjacentes, Minas Gerais. São Paulo. 243p. Tese (Doutorado) - Instituto de Geociências, Universidade de São Paulo.

Endo I, Oliveira A.H., Peres G.G., Guimarães M.L.V., Lagoeiro L.E., Machado R., Zavaglia G., Rosas C.F. \& Melo R.J., 2005. Nappe Curral: Uma megaestrutura alóctone do Quadrilátero Ferrífero e controle da mineralização. In: X Simpósio Nacional de Estudos Tectonicos / IV International Symposium on Tectonics, 2005, Curitiba. Boletim de resumos expandidos, 2005. P.279-282.

Madeira T.J.A. \& Barbosa M.S.C., 2012. Inversão de dados magnetométricos aplicada a prospecção de ouro na porção nordeste do Quadrilátero Ferrífero. In: Simpósio Brasileiro de Geofísica, 11., 2012, Salvador. Anais...Salvador: SBGf, 2012. CD-ROM.

Ramsay J.G. 1967. Folding and Fracturing of Rocks. New York, McGraw-Hill Book Co. 568p.

Silva O.P., 1995. A mineração em Minas Gerais: passado, presente e futuro. Geonomos 3 (1): 77-86. 

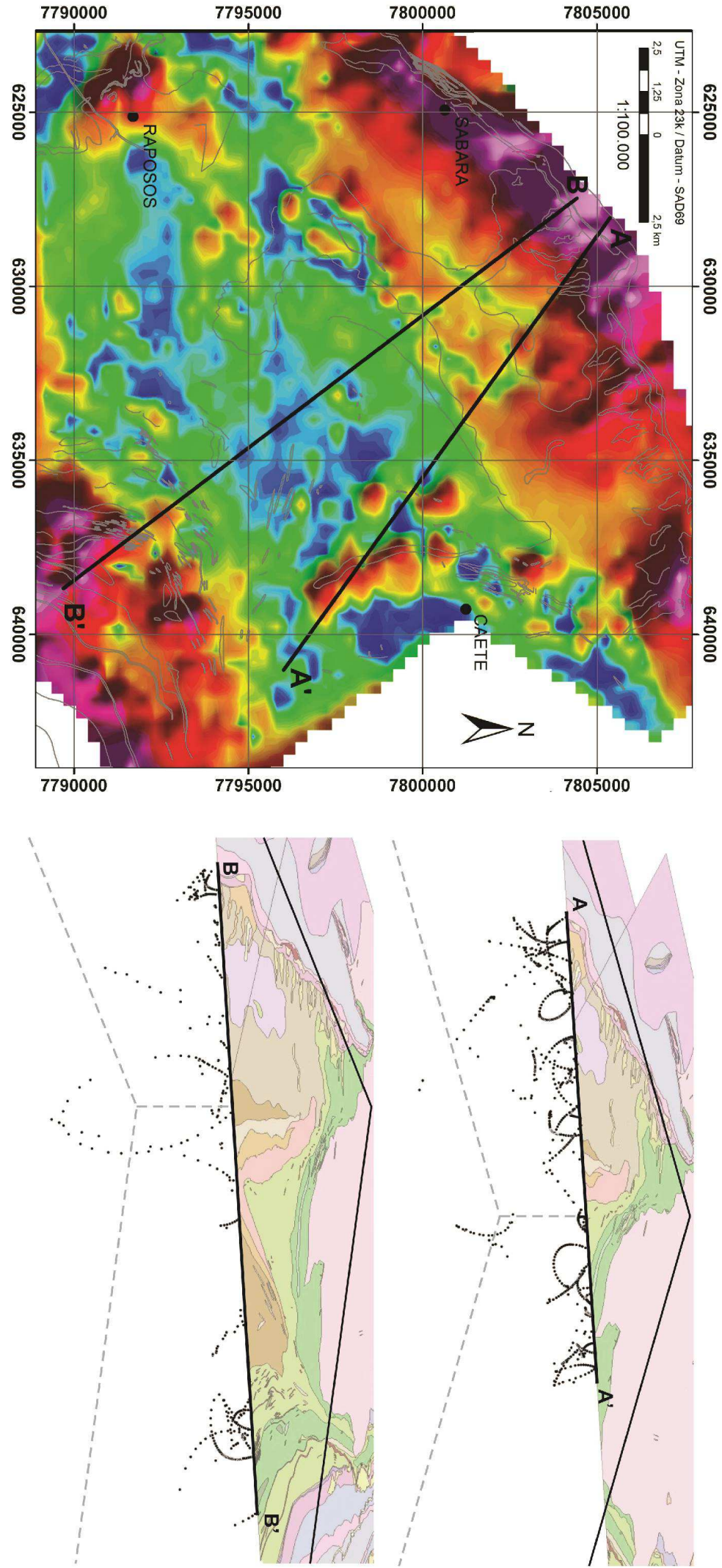

Figure 5- Mapa magnetométrico de Amplitude do Sinal Analítico e perfis de inversão integrados com a geologia. 


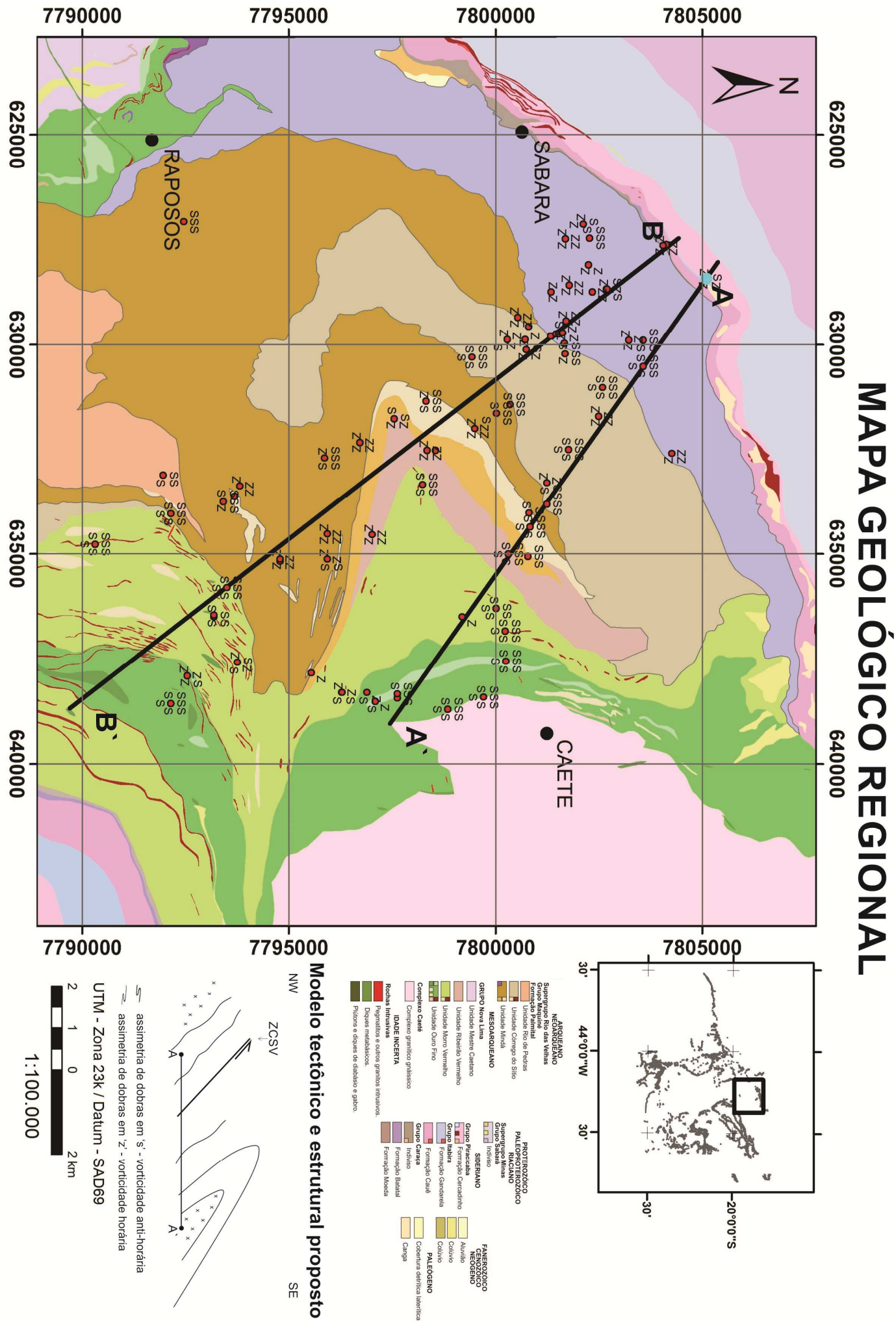

Figure 8 - Mapa geológico da área de estudos (modificado de Baltazar et al. 2005) e localização dos perfis de inversão magnetométricos e um modelo de evolução tectono-estrutural. 